Bangladesh Journal of Bioethics 2010; 1(1):3

\title{
Ethical Issues in Social Research
}

Prof. Ahmadullah Mia, Ph.D. Dean, Faculty of Sciences and Humanities, American World University, Dhaka Campus, Email: amia1941@gmail.com

The aims of social research include broadly understanding and explaining human behaviour and relations, influences of social institutions on behaviour, interactions between individuals' innate tendencies and social institutions, behaviour changes and conditions that lead to changes, scope of manipulations of the environment for positive social outcome, and impact of social interventions on individuals and groups or communities, etc. Varied methodologies are applied in social studies for theoretical development as well as advancing social inventions contributing to improvement of the living conditions of human population. Forms of studies are planned to suit the purpose. Also, methodology used in a study determines the type of study. Ethical issues in social studies emanate from the debate on the purpose of social studies - whether studies should primarily focus on building knowledge or application for change in the social conditions. Similarly methods applied to investigating into human life as making scientific exploration or influencing social conditions invite ethical controversy. Values that guide social research contain ethical elements, which are unavoidable, like research in any other field. Social research concerned with human being is always likely be plagued by controversy on ethical judgment. The only way to bypass the problem is to give priority consideration to 'those who the research is meant for'. 